\title{
Mitigation of nonpoint source pollution in rural areas: From control to synergies of multi ecosystem services
}

\author{
Yonghong $\mathrm{Wu}^{\mathrm{a}}$, Junzhuo Liu ${ }^{\mathrm{a}}$, Renfang Shen ${ }^{\mathrm{a}}$, Bojie $\mathrm{Fu}^{\mathrm{b}, *}$ \\ a State Key Laboratory of Soil and Sustainable Agriculture, Institute of Soil Science, Chinese Academy of Sciences, 71 East Beijing Road, Nanjing 210008, China \\ b State Key Laboratory of Urban and Regional Ecology, Research Center for Eco-Environmental Sciences, Chinese Academy of Sciences, Beijing 100085, China
}

\section{H I G H L I G H T S}

- NPS pollution loading has been the main contributor to surface water eutrophication.

- Source reduction, process retention and aquatic ecosystem restoration play important roles in mitigating NPS.

- Technology developed based on solid-, liquid- and bio-phases is suggested to decrease NPS pollution.

- Management based on framework of ecosystem services is recommended to reduce NPS pollution.
G R A P H I C A L A B S T R A C T

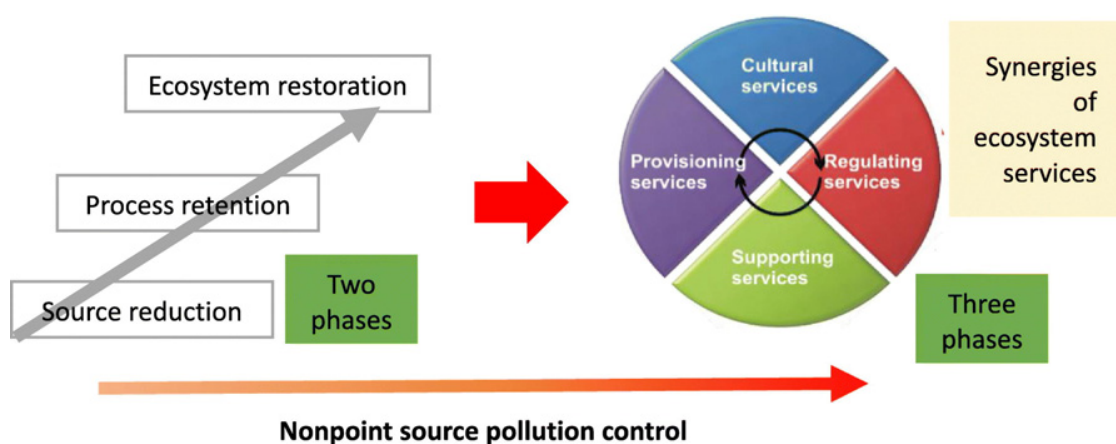

Nonpoint source pollution control

\section{A R T I C L E I N F O}

\section{Article history:}

Received 29 May 2017

Received in revised form 10 July 2017

Accepted 11 July 2017

Available online 27 July 2017

Editor: Jay Gan

Keywords:

Nonpoint source pollution

Formation

Three phases

Ecosystem service

\begin{abstract}
A B S T R A C T
Nonpoint source (NPS) pollution produced by human activities in rural areas has induced excessive nutrient input into surface waters and the decline of water quality. The essence of NPS pollution is the transport of nutrients between soil and water. Traditional NPS pollution control strategies, however, are mainly based on the solid and liquid phases, with little focus on the bio-phase between water and soil. The pollutants produced from NPS can be regarded as a resource if recycled or reused in an appropriate way in the agricultural ecosystem. This mini review proposes novel strategies for NPS pollution control based on three phases (liquid, solid and bio-phase) and highlights the regulating services of an agricultural ecosystem by optimizing land use/cover types.
\end{abstract}

(c) 2017 Elsevier B.V. All rights reserved.

\section{Background}

Pollutant inputs to surface waters including rivers, lakes, and oceans are classified as point or nonpoint sources. Due to the ease in monitoring the discharge and concentration of the pollutants, point sources are relatively simple to regulate and control by treatment at the source

\footnotetext{
* Corresponding author.

E-mail address: bfu@rcees.ac.cn (B. Fu).
}

(Rissman and Carpenter, 2015). Nonpoint inputs, however, often derive from extensive areas of land and are transported overland, underground, or even through the atmosphere to receiving water bodies (Ahmad et al., 2016; Jia et al., 2016), making them difficult to measure and control. Generally, agricultural sources including agricultural fields, livestock and poultry, aquaculture, rural runoff, and diffuse domestic wastewater are the main contributors to nonpoint source (NPS) pollution, especially in developing countries (Jia et al., 2016; Ongley et al., 2010; Sun et al., 2012). For instance, a national pollution census bulletin of China (2010) indicated that chemical oxygen demand (COD), total nitrogen 
(TN) and total phosphorus (TP) emissions from agricultural fields, livestock and poultry, and aquaculture in 2007 were 13.24, 2.70, and 0.28 million tons per year, respectively (Fig. 1), and the COD emission had exceeded that from industry (5.64 million tons per year). Specifically, livestock and poultry are the main contributors of COD (12.68 million tons per year), while TN and TP are mainly produced from agricultural fields and livestock and poultry. In mountainous areas, inappropriate land use and the consequent water loss and soil erosion are responsible for NPS pollution (Liu et al., 2016a; Zhai et al., 2014). In short, NPS pollution has been the one of main contributors to surface water eutrophication for many years and threatens the safety of surface water ecosystems (Zhang et al., 2017).

\section{Essence of NPS pollution formation and development}

With social and economic development, the industrial structure and lifestyles in rural areas have been under continuous change (Long and Liu, 2016; Sun et al., 2012). As a consequence, NPS emissions, including from domestic and agricultural sources, have been increasing and have heavily polluted surface water (Rissman and Carpenter, 2015). The formation and production of NPS pollution are highly dependent on meteorological events, e.g. rainfall, and are generally intermittent rather than continuous in nature (Kaushal et al., 2011; Wu et al., 2010b). NPS pollution is usually produced on expansive fields, which makes it impossible to track the specific sources, the time of production, and the pollutant concentrations (Ongley et al., 2010; Wu et al., 2011a).

Modernization, especially agricultural intensity, generally determines the essence and characteristics of the formation and production of NPS pollution (Wu et al., 2011a). For instance, since the 1980s, lifestyles and agricultural production structures in rural regions in China have experienced tremendous change, such as the increasing demand for meat, eggs, aquatic products, and refined fare (Sun et al., 2012). As a consequence, there have been great increases in source intensity and discharge frequency of NPS pollution, including diffuse domestic wastewater, nutrient rich runoff from agricultural fields, untreated agrowaste and wastewater from livestock, poultry and aquaculture (Long and Liu, 2016; Yang et al., 2013).

With these lifestyle changes, people in rural regions started to pursue higher and higher economic benefits to support their lives. Consequently, more and more chemical fertilizers and pesticides were used in agricultural fields. For instance, in the Taihu region, China, the nutrient input rate is $270-375 \mathrm{~kg} \mathrm{~N} \mathrm{ha}^{-2}$ for rice, $225-350 \mathrm{~kg} \mathrm{~N}^{-2}$ for wheat, and 60-150 kg P ha ${ }^{-2}$ for both crops, with rice yield of $21-28 \mathrm{~kg} \mathrm{~kg}^{-1} \mathrm{~N}$ and wheat yield of only $11-13 \mathrm{~kg} \mathrm{~kg}^{-1} \mathrm{~N}$ (Yang et al., 2013). The grain production in California, USA was 33-42 $\mathrm{kg} \mathrm{kg}^{-1} \mathrm{~N}$ (Eagle et al., 2000). A 50 years trend analysis in $\mathrm{N}$ use efficiency of world cropping systems indicated that $\mathrm{N}$ loss was over $50 \mathrm{~kg} \mathrm{~N} \mathrm{ha}^{-2} \mathrm{yr}^{-1}$ in most of Europe, the USA, India and China (Lassaletta et al., 2014). Globally, the low utilization efficiency of nutrients has induced increasing emissions of nitrogen and phosphorus in runoff from agricultural fields. The release of

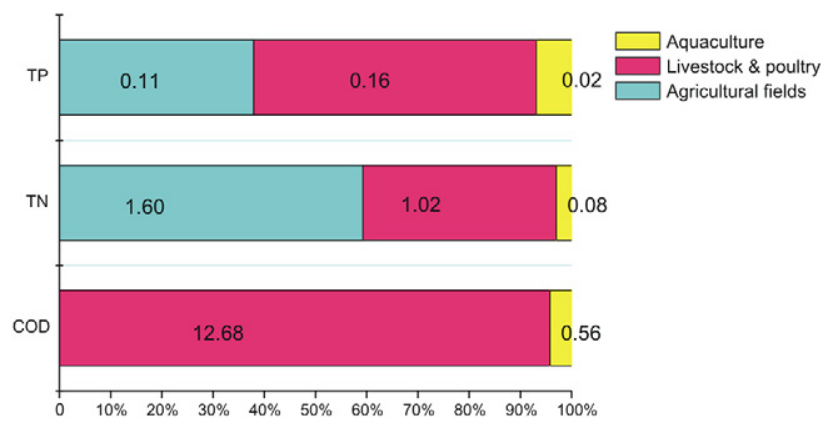

Fig. 1. The COD, TN and TP emissions (million tons per year) from NPS including agricultural fields, livestock and poultry, and aquaculture in China in 2007. these nutrients from agricultural fields has become the main source of NPS pollution (Wu et al., 2011a).

In addition to the runoff from agricultural fields, water and soil loss, especially in mountainous regions, is another main contributor to NPS pollution as the nutrients are usually removed by the lost soil which acts as the carrying substrate (Shen et al., 2014; Volk et al., 2017). Wu et al. (2011a) reported that water and soil loss contributed $7.7 \%$ and $29.7 \%$ to nitrogen and phosphorus loss, respectively, in the Dianchi region.

In summary, the formation and production of NPS pollution involves the transport and transformation of pollutants (i.e. nitrogen and phosphorus) between soil and water (Wu et al., 2011a; Yang et al., 2013). In intensive agricultural fields, the nutrient concentrations in both soil and water are relatively higher than in the surface water. This situation may drive or prompt nutrient transport processes from agricultural fields into surface water. The nutrient transport processes may be influenced by water and fertilizer management, precipitation, slope of land and other factors.

\section{The current NPS pollution control strategies}

Based on the formation and development processes of NPS pollution (i.e. production-flow-sink), three kinds of strategies have been proposed to control NPS pollution: (i) source reduction, including the optimization of fertilizer utilization and prevention of water and soil loss; (ii) pollutant retention during the transport process; and (iii) treatment and restoration of the polluted water pathway.

\subsection{Source reduction}

Similar to point source pollution control, source reduction is the key and most effective strategy for NPS pollution control (Ribaudo et al., 2001). Excessive fertilizer input is directly attributable to the emission of nitrogen and phosphorus from agricultural fields, due to the low nutrient utilization efficiency (Sun et al., 2012). Accordingly, source reduction strategy practices mainly involve the optimization of nutrient and water management, nutrient utilization efficiency improvement and fertilizer input reduction, water saving irrigation and runoff control (Ribaudo et al., 2001; Wu et al., 2011a; Xia et al., 2014; Yang et al., 2013). Moreover, water and soil conservation (e.g. conservation tillage, no-tillage, grass-crop rotation), especially in mountainous areas, is another key way to reduce soil erosion and runoff, and thereby the formation of NPS pollution in agricultural fields (Xia et al., 2014).

\subsection{Process retention}

Process retention technologies provide a second defense against water pollution by trapping and filtering pollutants that have left the field before they reach a stream or river. To date, process retention technologies include ecological ditches (Fig. 2A), buffer strips (Fig. 2B), vegetated ponds (Fig. 2C) and constructed wetlands (Fig. 2D) (Grismer, 2006; Wu et al., 2013). Generally, ecological ditches are one of the most effective technologies for nutrient retention in agricultural fields. Ecological ditches contain ditch plants, small dams (5-8 cm high) and filter boxes filled with substrates (Fig. 2E). In the ecological ditches, nutrients, including nitrogen and phosphorus, in the drainage can be removed in various ways including interception, adsorption, assimilation or denitrification, and this has been widely applied in the Taihu region in China ( $\mathrm{Wu}$ et al., 2013, 2011a; Xiong et al., 2015).

\subsection{Aquatic ecosystem restoration}

Here the aquatic ecosystem refers to the polluted water pathway, such as canals, ditches, ponds and streams in agricultural areas, rather than the final destination waters such as lakes and reservoirs. Although effective measures can be taken to reduce fertilizer input and retain 

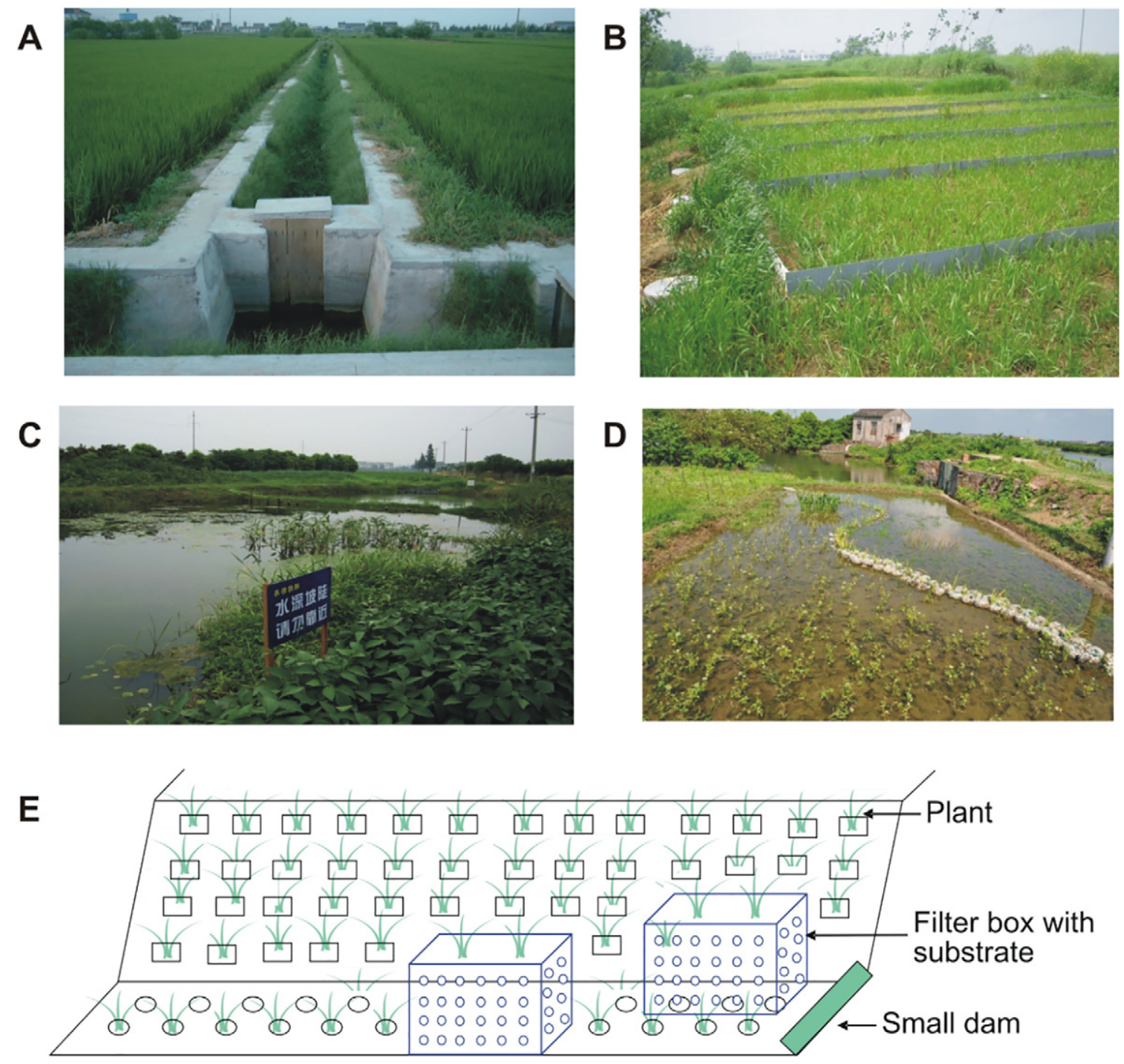

Fig. 2. A: Ecological ditches; B: Buffer strips; C: Vegetated ponds; D: Constructed wetland; E: Schematic drawing of the ecological ditches.

pollutants during transport processes, a significant amount of organic matter, nitrogen and phosphorus will unavoidably be released into these water pathways through which the runoff of NPS pollution passes (Liu et al., 2016c). Therefore, treatment of the surface water is needed to restore the aquatic ecosystem and improve water quality. Treatment and remediation of the canals, ditches and streams is the last strategy and defense for agricultural NPS pollution control. To date, several restoration technologies including ecological floating beds, eco submersible dams, riparian wetlands and submerged plant purification technologies have been developed and widely used (Audet et al., 2014; Liu et al., 2016c; Wu et al., 2011b). However, these technologies usually require long hydraulic retention times for nitrogen and phosphorus removal which limits their application in the restoration of surface water.

\section{Perspectives}

Nutrients released from NPS can be regarded as a type of resource if they can be properly recycled. The microbial communities at the interface between soil and water play important roles in nutrient transformation and should be considered in the development of novel strategies for NPS pollution control, such as nutrient utilization optimization and nutrient recycling. Moreover, similar to other ecosystems, the agricultural ecosystem has multiple ecoservice functions, including retaining nutrients and water in the soil, and can be optimized to synergize ecosystem service functions to retain the excessive nutrients for further utilization.

\subsection{Technology developed based on solid-, liquid- and bio-phases}

As described above in Section 2, nutrient transport and transformation between soil and water phases is the essence of NPS pollution formation and production. Traditionally, all the strategies and measures for NPS pollution control are based on two phases: solid and liquid phases (Fig. 3A) (Grismer, 2006; Wu et al., 2011a; Yang et al., 2013). The third phase, the bio-phase composed of bacteria, microalgae, fungi and many other microorganisms between the solid and liquid phases in nature, especially in shallow aquatic ecosystems. The bio-phase is usually neglected in the studies of NPS pollution formation and control, however it plays non-negligible roles in nutrient transformation between water and soil (Fig. 3B) (Lu et al., 2016; Wu et al., 2016). A typical example is the paddy fields, in which filamentous algae grow well by attaching to the soil surface and forming microbial aggregates with bacteria, fungi, and other micro- and meso-organisms (e.g. protozoa and metazoa), known as periphytic biofilms (Wu et al., 2016). In paddy fields, periphytic biofilms are the only way through which nutrient transformation and exchange can occur between the soil and overlying water (Lu et al., 2017, 2016). 
(A)

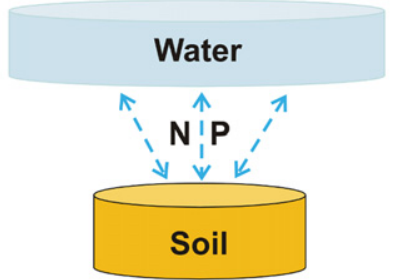

(B)

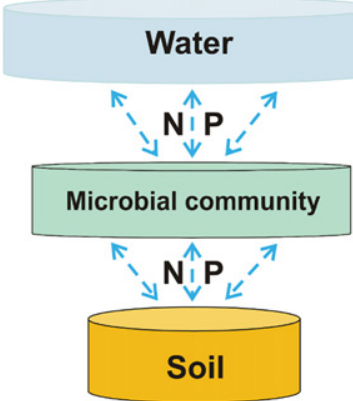

Fig. 3. A: Traditional "two phases (solid and liquid)" pathways for nutrient (i.e. nitrogen and phosphorus) transport in NPS pollution studies; B: Nutrient (i.e. nitrogen and phosphorus) transport pathways based on "three phases (solid, liquid and bio)" in NPS pollution studies.

The bio-phase plays important roles in nutrient transport between the solid and liquid phases as many biochemical and/or chemical reactions involved in nutrient transformation occur in the bio-phase. Microorganisms take up nitrogen and phosphorus for their growth and retain the nutrients as part of their biomass, such as protein (Liu and Vyverman, 2015; Liu et al., 2017; Sood et al., 2015). After the microorganisms die and biomass decays, nitrogen will be released back into soil as organic fertilizer, and the bio-phase can be regarded as a temporary sink of nutrients and a slow-release fertilizer. Studies also indicate that many cyanobacteria species are capable of nitrogen fixing to improve nitrogen availability in agricultural fields (Pereira et al., 2009). In turn, nutrient utilization efficiency is improved and nutrient discharge from agricultural fields (e.g. paddy fields) is reduced. Based on this concept, microbial fertilizer based on algae (Mulbry et al., 2007) and slow release bioorganic fertilizer using periphytic biofilms have been developed $(\mathrm{Wu}$, 2013; Wu and Yang, 2012).

The bio-phase can also change $\mathrm{pH}$ and redox conditions of soil and water through metabolic activities including photosynthesis of microalgae and respiration of microorganisms (Liu et al., 2016b). As a consequence, it will drive ammonia volatilization via $\mathrm{pH}$ increase, nitrification or denitrification and phosphorus precipitation to an extent, and thereby reduce nutrient concentration in the runoff from agricultural fields (Lu et al., 2014; Su et al., 2016). Additionally, there are many microbial organisms in the bio-phase, such as phosphate solubilizing bacteria (PSB), which can solubilize Ca-P to activate the occluded phosphorus in soil and thereby reduce phosphorus input (Maitra et al., 2015). Many microbial species can also secrete extracellular enzymes to hydrolyze phosphate from dissolved organic molecules to increase the phosphorus bioavailability (Ellwood et al., 2012).

Generally, the "three-phase" (liquid-, solid- and bio-phase) concept is more objective and closer to reality under natural conditions than the "two-phase" (liquid-, and solid-phase). Accordingly, in addition to the slow release biofertilizer, many other novel technologies can be developed based on solid-, liquid- and bio-phases and have high potential for NPS pollution control at both sources and processes. Microbial communities with high nutrient transformation capacity can be selected or synthesized and then cultivated on artificial substrates (Liu et al., 2017). After cultivation, they can be put in agricultural fields (e.g. paddy fields) to improve nutrient utilization efficiency and thereby reduce fertilizer input. Microbial communities with substrates can also be installed in ecological ditches to retain nutrients from runoff before they reach surface waters (Wu et al., 2010a).

\subsection{Management based on a framework of ecosystem services}

Ecosystem services refer to the benefits from all types of ecosystems (including agricultural ecosystems) and are classified into supporting, provisioning, regulating and cultural services (Fig. 4) (Fu et al., 2013). Among these, regulating services including purification of water and air, carbon sequestration, and waste decomposition (Eldridge and Delgado-Baquerizo, 2017), can be adopted for NPS pollution control. This can include reduction of NPS pollution production and retaining pollutants during their transport process. In other words, as a complex community composed of crops, trees, animals, surface water and land, the agricultural ecosystem has a great capacity to retain and consume nutrients itself (Fu et al., 2011, 2000).

Accordingly, the strategies for NPS pollution control should be at a regional scale, considering the whole region as an indivisible ecosystem and making use of the water and nutrient holding functions of the ecosystem. However, currently used technologies, such as water saving irrigation, conservation tillage and ecological ditches, only focus on a small part of the agricultural ecosystem (Rissman and Carpenter, 2015; Sharpley et al., 2007). Therefore, future work should be carried out at the ecosystem level with the aim of maintaining and improving the regulating services of the ecosystem, especially improving its water and nutrient retaining capacity with the ultimate objective of reducing NPS pollution production.

Because the biogeochemical transformation processes of nutrients are closely related to soil properties and utilization, land use/cover types of an agricultural ecosystem contribute greatly to the formation and production of NPS pollution (de Oliveira et al., 2017; Strehmel et al., 2016). Excessive nutrient input may cause eutrophication and decline in surface water quality, however, nutrients discharged from NPS (e.g. agricultural fields) can be regarded as resources to be reused since nutrients are essential for the growth of plants (e.g. trees, grass and waterweeds) in both aquatic and terrestrial ecosystems (Grismer, 2006; Wu et al., 2010a). To make full use of the multiple functions of the agricultural ecosystem for NPS pollution control, appropriate land use patterns should be prioritized, such as changing sloping farmland into woodland, building grassland filtering bands, no-tillage stubble, building multi-pond systems, and optimizing the distribution of residential areas (Fig. 4) (Ekroos et al., 2014; Zhang et al., 2013). This will lead to improved nutrient utilization capacity, reductions in water and soil loss and domestic wastewater production, retaining of the nutrients in the ecosystem before they reach surface water, and increased agricultural production (Fig. 4). Ultimately, the NPS pollutant production is minimized with improvements in both environmental and economic benefits, due to the enhancement of multiple ecosystem services synergies.

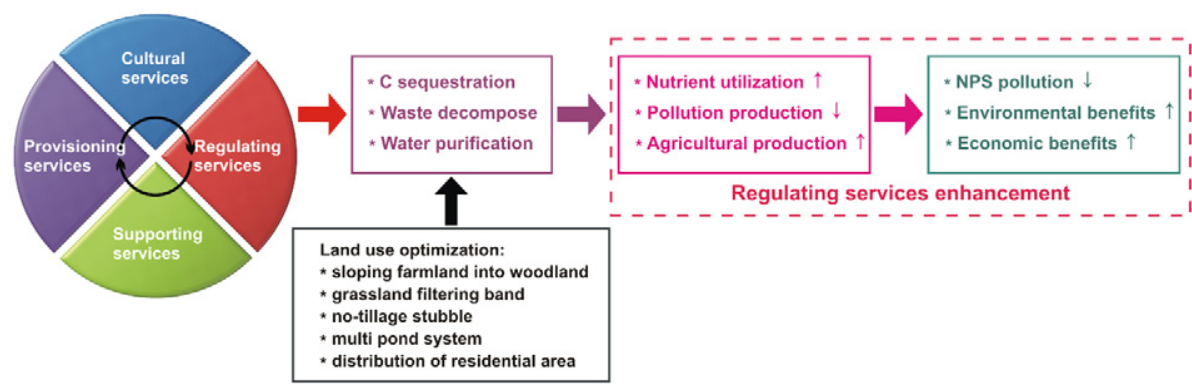

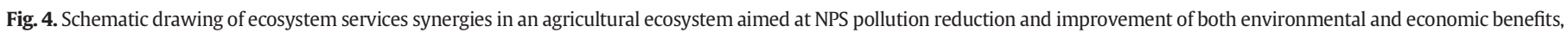
based on land use optimization. 


\section{Conclusions}

As a non-negligible phase between water and soil in agricultural ecosystems (e.g. paddy fields), the bio-phase composed of microbial organisms plays important roles in nutrient transport between water and soil and thereby the production of nonpoint source (NPS) pollution. However, the bio-phase is usually neglected or underestimated in NPS pollution control. The pollutants produced from NPS can be regarded as a resource if recycled in an appropriate way in the agricultural ecosystem. Based on three phases (liquid, solid and bio-phase), novel technologies can be developed by using the regulating services of an agricultural ecosystem via optimizing land use/cover types.

\section{Acknowledgements}

This work was supported by the State Key Development Program for Basic Research of China (2015CB158200), the National Natural Science Foundation of China (41422111, 31600097) and the Natural Science Foundation of Jiangsu Province, China (BK20150066). This work was also supported by the Hundred-Talent Program (Dr Junzhuo Liu) and Youth Innovation Promotion Association (2014269), Chinese Academy of Sciences, China.

\section{References}

Ahmad, Z.U., Sakib, S., Gang, D.D., 2016. Nonpoint source pollution. Water Environ. Res. 88 (10), 1594-1619.

Audet, J., Hoffmann, C.C., Andersen, P.M., Baattrup-Pedersen, A., Johansen, J.R., Larsen, S.E., et al., 2014. Nitrous oxide fluxes in undisturbed riparian wetlands located in agricultural catchments: emission, uptake and controlling factors. Soil Biol. Biochem. 68, 291-299.

de Oliveira, L.M., Maillard, P., de Andrade Pinto, E.J., 2017. Application of a land cover pollution index to model non-point pollution sources in a Brazilian watershed. Catena $150,124-132$.

Eagle, A.J., Bird, J.A., Horwath, W.R., Linquist, B.A., Brouder, S.M., Hill, J.E., et al., 2000. Rice yield and nitrogen utilization efficiency under alternative straw management practices. Agron. J. 92 (6), 1096-1103.

Ekroos, J., Olsson, O., Rundlöf, M., Wätzold, F., Smith, H.G., 2014. Optimizing agrienvironment schemes for biodiversity, ecosystem services or both? Biol. Conserv. $172,65-71$.

Eldridge, D.J., Delgado-Baquerizo, M., 2017. Continental-scale impacts of livestock grazing on ecosystem supporting and regulating services. Land Degrad. Dev. 28 (4), 1473-1481.

Ellwood, N.T., Di Pippo, F., Albertano, P., 2012. Phosphatase activities of cultured phototrophic biofilms. Water Res. 46 (2), 378-386.

Fu, B.-J., Su, C.-H., Wei, Y.-P., Willett, I.R., Lü, Y.-H., Liu, G.-H., 2011. Double counting in ecosystem services valuation: causes and countermeasures. Ecol. Res. 26 (1), 1-14

Fu, B., Chen, L., Ma, K., Zhou, H., Wang, J., 2000. The relationships between land use and soil conditions in the hilly area of the loess plateau in northern Shaanxi, China. Catena 39 (1), 69-78.

Fu, B., Wang, S., Su, C., Forsius, M., 2013. Linking ecosystem processes and ecosystem services. Curr. Opin. Environ. Sustain. 5 (1), 4-10.

Grismer, M.E., 2006. Vegetative Filter Strips for Nonpoint Source Pollution Control in Agriculture. UCANR Publications.

Jia, Z., Tang, S., Luo, W., Hai, Y., 2016. Water quality improvement through five constructed serial wetland cells and its implications on nonpoint-source pollution control. Hydrol. Sci. J. 61 (16), 2946-2956.

Kaushal, S.S., Groffman, P.M., Band, L.E., Elliott, E.M., Shields, C.A., Kendall, C., 2011. Tracking nonpoint source nitrogen pollution in human-impacted watersheds. Environ. Sci. Technol. 45 (19), 8225-8232.

Lassaletta, L., Billen, G., Grizzetti, B., Anglade, J., Garnier, J., 2014. 50 year trends in nitrogen use efficiency of world cropping systems: the relationship between yield and nitrogen input to cropland. Environ. Res. Lett. 9 (10), 105011.

Liu, J., Fu, B., Wang, Y., Xu, P., 2016a. Estimation and evaluation of non-point source pollutants loads in mountainous area of Sichuan. Trans. CSAE 32 (24), 218-225.

Liu, J., Liu, W., Wang, F., Kerr, P., Wu, Y., 2016b. Redox zones stratification and the microbial community characteristics in a periphyton bioreactor. Bioresour. Technol. 204 (0), 114-121.

Liu, J., Vyverman, W., 2015. Differences in nutrient uptake capacity of the benthic filamentous algae Cladophora sp., Klebsormidium sp. and Pseudanabaena sp. under varying N/ P conditions. Bioresour. Technol. 179 (0), 234-242.

Liu, J., Wang, F., Liu, W., Tang, C., Wu, C., Wu, Y., 2016c. Nutrient removal by up-scaling a hybrid floating treatment bed (HFTB) using plant and periphyton: from laboratory tank to polluted river. Bioresour. Technol. 207 (0), 142-149.

Liu, J., Wu, Y., Wu, C., Muylaert, K., Vyverman, W., Yu, H.-Q., et al., 2017. Advanced nutrient removal from surface water by a consortium of attached microalgae and bacteria: a review. Bioresour. Technol. http://dx.doi.org/10.1016/j.biortech.2017.06.054.
Long, H., Liu, Y., 2016. Rural restructuring in China. J. Rural. Stud. 47, 387-391.

Lu, H., Liu, J., Kerr, P.G., Shao, H., Wu, Y., 2017. The effect of periphyton on seed germination and seedling growth of rice (Oryza sativa) in paddy area. Sci. Total Environ. 578 (0), 74-80.

Lu, H., Wan, J., Li, J., Shao, H., Wu, Y., 2016. Periphytic biofilm: a buffer for phosphorus precipitation and release between sediments and water. Chemosphere $144(0)$, 2058-2064.

Lu, H., Yang, L., Shabbir, S., Wu, Y., 2014. The adsorption process during inorganic phosphorus removal by cultured periphyton. Environ. Sci. Pollut. Res. 21 (14), 8782-8791.

Maitra, N., Manna, S.K., Samanta, S., Sarkar, K., Debnath, D., Bandopadhyay, C., et al., 2015 Ecological significance and phosphorus release potential of phosphate solubilizing bacteria in freshwater ecosystems. Hydrobiologia 745 (1), 69-83.

Mulbry, W., Kondrad, S., Pizarro, C., 2007. Biofertilizers from algal treatment of dairy and swine manure effluents: characterization of algal biomass as a slow release fertilizer. J. Veg. Sci. 12 (4), 107-125.

Ongley, E.D., Xiaolan, Z., Tao, Y., 2010. Current status of agricultural and rural non-point source pollution assessment in China. Environ. Pollut. 158 (5), 1159-1168.

Pereira, I., Ortega, R., Barrientos, L., Moya, M., Reyes, G., Kramm, V., 2009. Development of a biofertilizer based on filamentous nitrogen-fixing cyanobacteria for rice crops in Chile. J. Appl. Phycol. 21 (1), 135-144.

Ribaudo, M.O., Heimlich, R., Claassen, R., Peters, M., 2001. Least-cost management of nonpoint source pollution: source reduction versus interception strategies for controlling nitrogen loss in the Mississippi Basin. Ecol. Econ. 37 (2), 183-197.

Rissman, A.R., Carpenter, S.R., 2015. Progress on nonpoint pollution: barriers \& opportunities. Daedalus 144 (3), 35-47.

Sharpley, A.N., Krogstad, T., Kleinman, P.J., Haggard, B., 2007. Managing natural processes in drainage ditches for nonpoint source phosphorus control. J. Soil Water Conserv. 62 (4), 197-206.

Shen, Z., Qiu, J., Hong, Q., Chen, L., 2014. Simulation of spatial and temporal distributions of non-point source pollution load in the Three Gorges Reservoir Region. Sci. Total Environ. 493, 138-146.

Sood, A., Renuka, N., Prasanna, R., Ahluwalia, A., 2015. Cyanobacteria as potential options for wastewater treatment. In: Ansari, A.A., Gill, S.S., Gill, R., Lanza, G.R., Newman, L. (Eds.), Phytoremediation. Springer International Publishing, pp. 83-93 10.1007/ 978-3-319-10969-5_8.

Strehmel, A., Schmalz, B., Fohrer, N., 2016. Evaluation of land use, land management and soil conservation strategies to reduce non-point source pollution loads in the Three Gorges region, China. Environ. Manag. 58 (5), 906-921.

Su, J., Kang, D., Xiang, W., Wu, C., 2016. Periphyton biofilm development and its role in nutrient cycling in paddy microcosms. J. Soils Sediments 17 (3), 810-819.

Sun, B., Zhang, L., Yang, L., Zhang, F., Norse, D., Zhu, Z., 2012. Agricultural non-point source pollution in China: causes and mitigation measures. Ambio 41 (4), 370-379.

Volk, M., Bosch, D., Nangia, V., Narasimhan, B., 2017. SWAT: Agricultural Water and Nonpoint Source Pollution Management at a Watershed Scale-Part II. Elsevier.

Wu, M., Tang, X., Li, Q., Yang, W., Jin, F., Tang, M., et al., 2013. Review of ecological engineering solutions for rural non-point source water pollution control in Hubei Province, China. Water Air Soil Pollut. 224 (5), 1561.

Wu, Y., 2013. The studies of periphyton: from waters to soils. Hydrology: Curr. Res. 4 (2) $1-2$.

Wu, Y., Hu, Z., Yang, L., 2010a. Hierarchical eco-restoration: a systematical approach to removal of COD and dissolved nutrients from an intensive agricultural area. Environ. Pollut. 158 (10), 3123-3129.

Wu, Y., Hu, Z., Yang, L., 2011a. Strategies for controlling agricultural non-point source pollution: reduce-retain-restoration (3R) theory and its practice. T. CSAE 27 (5), 1-6.

Wu, Y., Hu, Z., Yang, L., Graham, B., Kerr, P.G., 2011b. The removal of nutrients from nonpoint source wastewater by a hybrid bioreactor. Bioresour. Technol. 102 (3) 2419-2426.

Wu, Y., Kerr, P.G., Hu, Z., Yang, L., 2010b. Eco-restoration: simultaneous nutrient removal from soil and water in a complex residential-cropland area. Environ. Pollut. 158 (7) 2472-2477.

Wu, Y., Liu, J., Lu, H., Wu, C., Kerr, P., 2016. Periphyton: an important regulator in optimizing soil phosphorus bioavailability in paddy fields. Environ. Sci. Pollut. Res. Int. 23 (21), 21377-21384

Wu, Y., Yang, L., 2012. A prospectus for bio-organic fertilizer based on microorganisms: recent and future research in agricultural ecosystem. In: Singh, R.P. (Ed.), Organic Fertilizers: Types, Production and Environmental Impact. Nova Science Publisher, New York

Xia, L., Liu, G., Ma, L., Yang, L., Li, Y., 2014. The effects of contour hedges and reduced tillage with ridge furrow cultivation on nitrogen and phosphorus losses from sloping arable land. J. Soils Sediments 14 (3), 462-470.

Xiong, Y., Peng, S., Luo, Y., Xu, J., Yang, S., 2015. A paddy eco-ditch and wetland system to reduce non-point source pollution from rice-based production system while maintaining water use efficiency. Environ. Sci. Pollut. Res. Int. 22 (6), 4406.

Yang, L.-Z., Feng, Y.-F., Shi, W.-M., Xue, L.-H., Wang, S.-Q., Song, X.-F., et al., 2013. Review of the advances and development trends in agricultural non-point source pollution control in China. Chinese J. Eco-Agr. 21 (1), 96-101.

Zhai, X., Zhang, Y., Wang, X., Xia, J., Liang, T., 2014. Non-point source pollution modelling using soil and water assessment tool and its parameter sensitivity analysis in Xin'anjiang catchment, China. Hydrol. Process. 28 (4), 1627-1640.

Zhang, P., Liu, Y., Pan, Y., Yu, Z., 2013. Land use pattern optimization based on CLUE-S and SWAT models for agricultural non-point source pollution control. Math. Comput Model. 58 (3), 588-595.

Zhang, W., Jin, X., Liu, D., Lang, C., Shan, B., 2017. Temporal and spatial variation of nitrogen and phosphorus and eutrophication assessment for a typical arid river - Fuyang River in northern China. J. Environ. Sci. (China) 55 (0), 41-48. 